Article

\title{
Hydrodynamic Compatibility of Hyaluronic Acid and Tamarind Seed Polysaccharide as Ocular Mucin Supplements
}

\author{
Taewoo Chun ${ }^{1}$, Thomas MacCalman ${ }^{1}$, Vlad Dinu ${ }^{1}$, Sara Ottino ${ }^{2}{ }^{(0)}$, Mary K. Phillips-Jones ${ }^{1, *}$ \\ and Stephen E. Harding 1,3,*(D) \\ 1 National Centre for Macromolecular Hydrodynamics (NCMH), School of Biosciences, \\ University of Nottingham, Sutton Bonington LE12 5RD, UK; stxtc16@exmail.nottingham.ac.uk (T.C.); \\ stxtm22@exmail.nottingham.ac.uk (T.M.); sbavd@exmail.nottingham.ac.uk (V.D.) \\ 2 Farmigea S.P.A, Via G.B. Oliva, 6/8 - 56121 Pisa, Italy; s.ottino@farmigea.it \\ 3 Cultural History Museum, University of Oslo, Postboks 6762, St. Olavs plass, 0130 Oslo, Norway \\ * Correspondence: mary.phillips-jones@nottingham.ac.uk (M.K.P.-J.); \\ steve.harding@nottingham.ac.uk (S.E.H.)
}

Received: 1 September 2020; Accepted: 28 September 2020; Published: 2 October 2020

\begin{abstract}
Hyaluronic acid (HA) has been commonly used in eyedrop formulations due to its viscous lubricating properties even at low concentration, acting as a supplement for ocular mucin (principally MUC5AC) which diminishes with aging in a condition known as Keratoconjunctivitis sicca or "dry eye". A difficulty has been its short residence time on ocular surfaces due to ocular clearance mechanisms which remove the polysaccharide almost immediately. To prolong its retention time, tamarind seed gum polysaccharide (TSP) is mixed as a helper biopolymer with HA. Here we look at the hydrodynamic characteristics of HA and TSP (weight average molar mass $M_{w}$ and viscosity $[\eta]$ ) and then explore the compatibility of these polymers, including the possibility of potentially harmful aggregation effects. The research is based on a novel combination of three methods: sedimentation velocity in the analytical ultracentrifuge (SV-AUC), size-exclusion chromatography coupled to multiangle light scattering (SEC-MALS) and capillary viscometry. HA and TSP were found to have $M_{w}=(680 \pm 30) \mathrm{kg} / \mathrm{mol}$ and $(830 \pm 30) \mathrm{kg} / \mathrm{mol}$ respectively, and $[\eta]=(1475 \pm 30) \mathrm{ml} / \mathrm{g}$ and $(675 \pm 20) \mathrm{ml} / \mathrm{g}$, respectively. The structure of HA ranges from a rodlike molecule at lower molar masses changing to a random coil for $M_{\mathrm{W}}>800 \mathrm{~kg} / \mathrm{mol}$, based on the Mark-Houwink-Kuhn-Sakurada (MHKS) coefficient. TSP, by contrast, is a random coil across the range of molar masses. For the mixed HA-TSP systems, SEC-MALS indicates a weak interaction. However, sedimentation coefficient (s) distributions obtained from SV-AUC measurements together with intrinsic viscosity demonstrated no evidence of any significant aggregation phenomenon, reassuring in terms of eye-drop formulation technology involving these substances.
\end{abstract}

Keywords: molar mass; heterogeneity and conformation; analytical ultracentrifugation; light scattering; viscometry

\section{Introduction}

As people age, their production of ocular mucin containing lacrymal fluid-with its natural protective and lubricating properties for the surface of the eye-diminishes, a term known medically as Keratoconjunctivitis sicca or "dry eye". Solutions of polysaccharide in artificial tear drop formulations are popularly used to consolidate the mucin (of primarily type MUC5AC, also MUC2) to remove these symptoms. A problem with such formulations is how to prolong their residence time on the eye surface. The main reason for this problem is that ocular protective mechanisms (involving blinking, 
both basal and reflex lachrymation, and a drainage through nasolacrimal ducts) quickly eliminates these eye drops from the precorneal region, where such drugs are absorbed and work [1]. As a result, and depending on the severity, this can lead to the need for repeated administration [2]. Therefore, various studies have investigated novel preparations to overcome such disadvantages of currently available formulations. For example, based on the viscosity enhancing effects of gelatin, the grafting of thermoresponsive polymer segments onto proteinaceous networks has led to promising results [3] and, more recently, the lectin Helix pomatia agglutinin has been considered as an ocular mucoadhesive component [4]. The properties of a promising new glutathione-dependent polymeric hydrogel with good eye drop mucoadhesive properties has also been explored [5].

Another highly significant development has been the combination of hyaluronic acid (HA) and tamarind seed gum polysaccharide (TSP), whose medical benefits were first reported by Barabino et al. [6]. Of the two components, both natural polysaccharides, HA is a linear polyanionic molecule chemically grouped in a glycosaminoglycan and comprises the repeating dimer $\{\rightarrow 4)-\beta$-D-glucopyranosyluronic acid-( $1 \rightarrow 3)-N$-acetyl-2-amino-2-deoxy- $\beta$-D-glycopyranosyl- $(1 \rightarrow\}[7,8]$. When it comes to the current market situation, it has been reported [2] that $0.1-0.5 \%(w / v)$ HA solutions are available commercially as either active or inactive ingredients to supplement ocular fluid (see also refs [9] and [10]). Hammer and Burch [11] have suggested that 0.17\% HA showed superior protective effects as a coating on the eye compared to the highly viscous, more concentrated applications ( $1 \%$, equivalent to $10 \mathrm{mg} / \mathrm{mL}$ ) which transmit excessive shear force to endothelial cells. An alternative approach, which can also help with product stability issues is to use HA in a binary mixture with another polysaccharide. The second polysaccharide, TSP (Figure 1) is a nonionic, neutral and branched xyloglycan, which is comprised of a cellulose-like backbone, partially replaced at the O-6 position of its glucopyranosyl units with $\alpha$-D-xylopyranose [6,12].

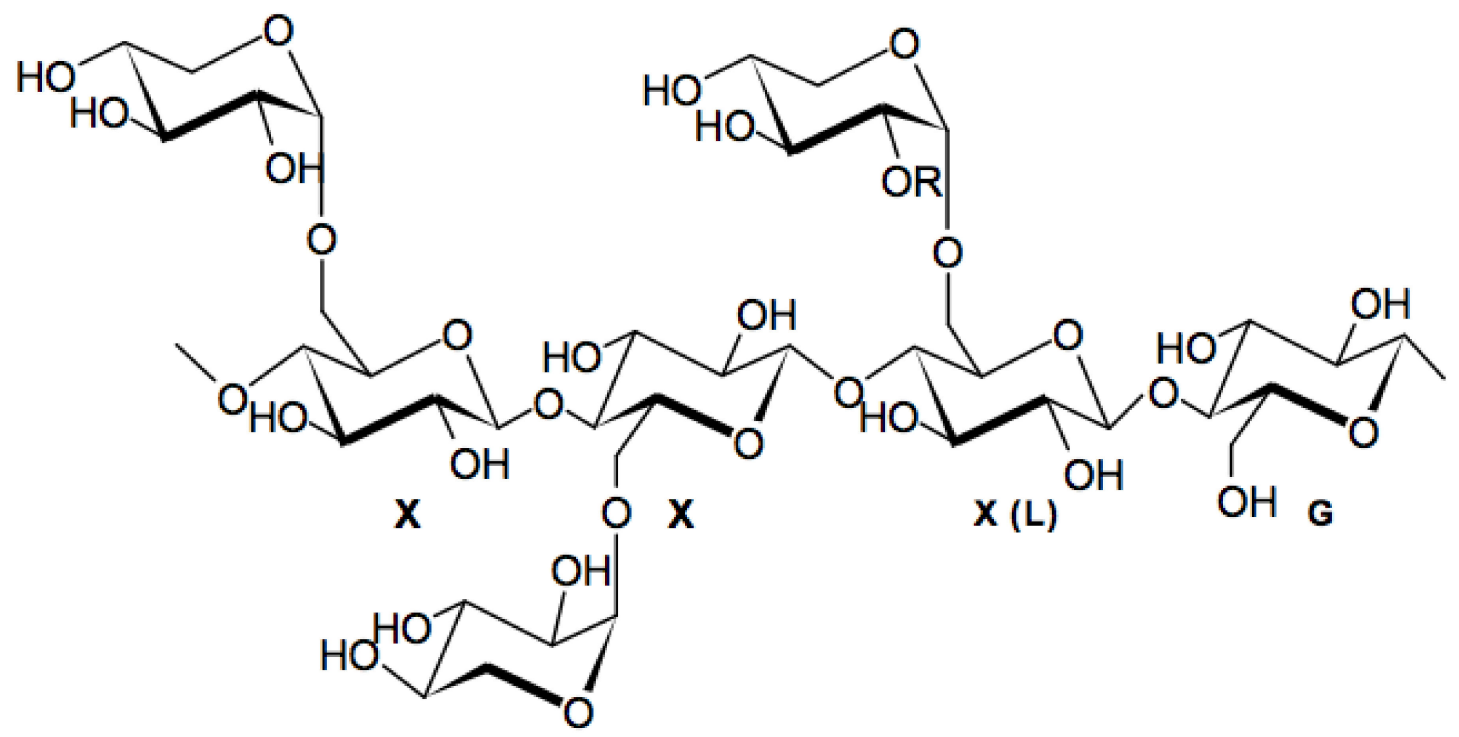

Figure 1. Chemical structure of tamarind seed xyloglucan; motif XXXG or $\beta$

A comparative study by Rolando and Valente [13] has indicated that both $0.5 \%$ and $1 \%$ solutions of TSP are comparable to $0.2 \%$ HA in terms of removing the symptoms of dry eye syndrome. Later, Barabino et al. [6] published their results with mixtures of HA and TSP, showing that this combination is effective in fixing the tear film on the cornea and repairing the endothelial damage in dry eye patients. One principal reason for these outcomes is that the structural similarity of TSP to transmembrane mucins (MUC1) on the eye surface could lead to its longer retention time [13].

-D-galactopyranose (motif XXLG). Adapted from [14]. 
In addition, recent evidence using nuclear magnetic resonance spectroscopy (NMR)—a powerful method for investigating macromolecular-ligand interactions [15] — has suggested that there is an interaction between these two polysaccharides [16]. We now seek to reinforce those observations by exploring the hydrodynamic compatibility and stability of these mixtures. Specifically we examine key hydrodynamic parameters such as the molar mass and intrinsic viscosity by size exclusion chromatography coupled to multiangle (laser) light scattering SEC-MALS and capillary viscometry, together with sedimentation velocity in the analytical ultracentrifuge, SV-AUC to assess the heterogeneity and interaction strength. The matrix-free method of analytical ultracentrifugation-with its huge dynamic range (molar masses from $10^{2}-10^{8} \mathrm{~g} / \mathrm{mol}$ ) is a key or "gold standard" method used to assess the molecular integrity of other biotherapeutic systems such as monoclonal antibodies (in terms of disassembly, denaturation or aggregation effects) and this is the first time that this method has been used to assess a dry-eye formulation. It has both a high separation and analysis ability without the need of columns or membranes $[17,18]$. We assess the change in the intrinsic viscosity with molar mass in order to estimate conformations of HA and TSP by SEC-MALS and viscometry, assess the state of self-association/aggregation of the individual components and for interaction/aggregation phenomena of the mixtures using SEC-MALS and SV-AUC, and finally investigate the stability of HA, TSP, and their mixtures.

Although polysaccharides such as cellulose acetate [19], proteins [20] and other natural polymers [21] are commonly used singly in biomedical applications, examples of the combined use of natural polymers for medicinal purposes are not so frequent but are increasing in importance. The HA-TSP system has provided a further good example [1,6,16,22], now reinforced by the present analytical ultracentrifuge-based study.

\section{Materials and Methods}

\subsection{Materials}

Hyaluronic acid and tamarind seed polysaccharide were supplied by Farmigea S.p.A., Pisa, Italy. HA or TSP samples were dissolved in a phosphate-chloride buffered saline solution (PBS, or "Paley buffer") at $\mathrm{pH} \sim 6.8$ adjusted to an ionic strength of $\mathrm{I}=0.1 \mathrm{~mol} / \mathrm{L}$ by the addition of $\mathrm{NaCl}$ [23].

Stock solutions of HA and TSP were prepared by stirring gently for $30 \mathrm{~min}$ followed by overnight dialysis at room temperature against a two-litre volume of PBS. The concentration, $c(\mathrm{~g} / \mathrm{mL})$ of the stock solution (either HA or TSP) was then measured using a differential refractometer (Atago DD7, Tokyo, Japan) set to zero with PBS, and using a refractive increment $\mathrm{d} n / \mathrm{d} c$ of $0.167 \mathrm{~mL} / \mathrm{g}$ for HA, and $0.152 \mathrm{~mL} / \mathrm{g}$ for TSP [24]. HA/TSP was prepared by adding equal volumes with various concentrations, resulting in a range of ratios (HA:TSP = 1:3, 1:1 and 3:1) and final concentrations $(4.0 \mathrm{mg} / \mathrm{mL}, 2.0 \mathrm{mg} / \mathrm{mL}$ and $1.0 \mathrm{mg} / \mathrm{mL}$ commensurate with concentrations used in formulations, and with materials remaining in solution (on the premise there are no significant irreversible aggregation/ complex formation interactions).

\subsection{Sedimentation Velocity in the Analytical Ultracentrifuge}

Sedimentation coefficients and sedimentation coefficient distributions were determined using the optimal XL-I analytical ultracentrifuge (Beckman Instruments, Palo Alto, CA, USA) with Rayleigh interference optics. Reference solvent or dialysate $(420 \mu \mathrm{L})$ and HA, TSP or HA/TSP samples $(400 \mu \mathrm{L})$ with different concentrations were injected into channels of $12 \mathrm{~mm}$, double-sectored cells with sapphire windows. Then these cells were loaded into an eight-hole rotor and centrifuged at a rotor speed of $45,000 \mathrm{rpm}$ at a temperature of $20.0^{\circ} \mathrm{C}$ for a run time of $\sim 24 \mathrm{~h}$. The data was analysed using the SEDFIT algorithm [25], which gives the sedimentation coefficient distribution, $g(s)$ versus $s_{T, b}$, where $s$ is the sedimentation coefficient, at temperature $T$ and in buffer $b$. The $s$ value was then corrected to standard solvent conditions (density and viscosity of water at $20.0^{\circ} \mathrm{C}$ ) to produce $s_{20, w}$ using the equation [26]:

$$
s_{20, w}=\left\{\left(1-\bar{v} \rho_{20, w}\right) /\left(1-\bar{v} \rho_{T, b}\right)\right\}\left\{\eta_{T, b} / \eta_{20, w}\right\} \cdot s_{T, b}
$$


where $\bar{v}$ is the partial specific volume of each sample. To eliminate the effect of nonideality, the Gralén equation was used for the extrapolation [27]:

$$
\frac{1}{s_{20, w}}=\frac{1}{s_{20, w}^{0}}\left(1+k_{s} c\right)
$$

where $k_{s}$ is the Gralén coefficient $(\mathrm{mL} / \mathrm{g})$.

\subsection{Size Exclusion Chromatography Coupled to Multiangle Laser Light Scattering (SEC-MALS)}

Weight average molar masses $\left(M_{\mathrm{W}}\right)$ of HA, TSP and HA/TSP were estimated by SEC-MALS [7,14,28,29]. The solvent/ buffer was pumped at a steady flow rate of $0.5 \mathrm{~mL} / \mathrm{min}$ through a column (Shodex LB-805 and), which was protected by a guard column (Shodex LB-G6B), coupled on-line to MALS (Dawn Heleos-11), a differential pressure viscometer (ViscoStar-11) and refractive index (Optilab rEX) detectors (Wyatt Technology, Santa Barbara, CA, USA). After being filtered through a $0.2 \mu \mathrm{m}$ syringe filter (Whatman, Maidstone, England), the solutions of the HA, TSP, and HA/TSP sample prepared at a concentration of $1.24 \mathrm{mg} / \mathrm{mL}, 0.68 \mathrm{mg} / \mathrm{mL}$, and $1.0 \mathrm{mg} / \mathrm{mL}$ (HA:TSP $=1: 1$ ) respectively, were injected into the size exclusion system using the Spark-Holland Marathon Basic autosampler to dilute on the column. ASTRA ${ }^{\mathrm{TM}}$ (Version 6.2) software (Wyatt Technology, Santa Barbara, CA, USA) was used to analyse the data. Apparent weight average molar mass $\left(M_{\mathrm{w}, \mathrm{app}}\right)$ was calculated by using a linear fit to the Zimm model [30]:

$$
\frac{K c}{R_{\theta}}=\left(\frac{1}{M_{w}}+2 B c\right)\left[1+\frac{16 \pi^{2} \overline{R_{\mathrm{g}}^{2}}}{3 \lambda^{2}} \sin ^{2} \frac{\theta}{2}\right]
$$

where $K$ is an experimental constant dependent on the wavelength of the light and the refractive index increment of the polysaccharide, $R_{\theta}$ is the Rayleigh ratio used to determine the ratio of the integrity of light scattered by a macromolecule at an angle $\theta$ to that of the incident radiation, $B$ is the second virial coefficient $\left(\mathrm{mL} \cdot \mathrm{mol} \cdot \mathrm{g}^{-2}\right), R_{\mathrm{g}}$ is the radius of gyration $(\mathrm{cm})$ [31].

$M_{\mathrm{W}, \text { app }}$ is obtained from the intercept [29]. We make the reasonable assumption that correction for thermodynamic nonideality was assumed to be unnecessary due to the high dilutions on the SEC columns (see, for example ref [32]) and hence $M_{\mathrm{W}}$ the "ideal" molar mass $\sim M_{\mathrm{w}, \mathrm{app}}$.

\subsection{Capillary Viscometry}

HA solutions ranging from 0.08 to $0.62 \mathrm{mg} / \mathrm{mL}$, TSP solutions (from 0.03 to $1.91 \mathrm{mg} / \mathrm{mL}$ ), and HA/TSP solutions (1 to $4 \mathrm{mg} / \mathrm{mL}$ ) were analysed using a semiautomated viscosity measuring system (AVS 400, Schott Geräte, Hofheim, Germany) at a temperature of $20.00^{\circ} \mathrm{C}$ in a $2 \mathrm{~mL}$ Ostwald viscometer (Table 1). Considering the fact that, because of low concentration $(<2 \mathrm{mg} / \mathrm{mL})$, a density correction is considered to be redundant [14], the relative viscosity, $\eta_{\text {rel }}$, was estimated to be the ratio of the flow time of the solution $t(\mathrm{sec})$ to that of solvent $t_{0}$ :

$$
\eta_{\mathrm{rel}} \approx \frac{t}{t_{0}}=\eta_{\mathrm{sp}}+1
$$

where $\eta_{\mathrm{sp}}$ is the specific viscosity [33]. Then the reduced specific viscosity, $\eta_{\mathrm{red}},(\mathrm{mL} / \mathrm{g})$ and the inherent viscosity, $\eta_{\text {inh }},(\mathrm{mL} / \mathrm{g})$ were obtained from:

$$
\begin{aligned}
& \eta_{\text {red }}=\left(\eta_{\text {rel }}-1\right) / c \\
& \eta_{\text {inh }}=\left(\ln \eta_{\text {rel }}\right) / c
\end{aligned}
$$

where $c(\mathrm{~g} / \mathrm{mL})$ is the solute concentration [33]. 
Table 1. Hydrodynamic properties of hyaluronic acid (HA) and tamarind seed gum polysaccharide (TSP) in PBS “Paley” buffer.

\begin{tabular}{ccc}
\hline Sample & HA & TSP \\
\hline$[\eta](\mathrm{ml} / \mathrm{g})$ & $1475 \pm 30$ & $675 \pm 20$ \\
$s_{20, \mathrm{w}}^{0}(\mathrm{~S})$ & $4.7 \pm 0.2$ & $5.4 \pm 0.2$ \\
$a$ & $1.1^{*}$ & 0.63 \\
$10^{-3} \times \mathrm{M}_{\mathrm{w}}(\mathrm{g} / \mathrm{mol})$ & $680 \pm 30$ & $830 \pm 30$ \\
$10^{-3} \times \mathrm{M}_{\mathrm{Z}}(\mathrm{g} / \mathrm{mol})$ & 730 & 940 \\
$10^{-3} \times \mathrm{M}_{\mathrm{n}}(\mathrm{g} / \mathrm{mol})$ & 640 & 680 \\
$\mathrm{M}_{\mathrm{z}} / \mathrm{M}_{\mathrm{w}}$ & 1.1 & 1.1 \\
$\mathrm{M}_{\mathrm{w}} / \mathrm{M}_{\mathrm{n}}$ & 1.1 & 1.2 \\
\hline \multicolumn{3}{c}{}
\end{tabular}

These $\eta_{\text {red }}$ and $\eta_{\text {inh }}$ can be extrapolated to zero concentration in order to eliminate nonideality effect, leading to the intrinsic viscosity $[\eta]$ :

$$
\begin{aligned}
& \eta_{\text {red }}=[\eta]\left(1+K_{\mathrm{H}} \cdot[\eta] \cdot c\right) \\
& \eta_{\text {inh }}=[\eta]\left(1-K_{\mathrm{K}} \cdot[\eta] \cdot c\right)
\end{aligned}
$$

where $K_{\mathrm{H}}$ is the Huggins constant [34] and $K_{\mathrm{K}}$ is the Kraemer constant [35]. Additionally, a combination of Equations (7) and (8) was used [36]:

$$
[\eta] \simeq \frac{1}{c} \cdot\left[2 \eta_{\mathrm{sp}}-2 \ln \left(\eta_{\mathrm{rel}}\right)\right]^{1 / 2}
$$

\section{Results and Discussion}

\subsection{Comparison of Hydrodynamic Properties of HA and TSP of the Preparations}

Table 1 summarizes the hydrodynamic properties of the hyaluronic acid and tamarind seed gum preparations (supplied by Farmigea AG) in the phosphate-chloride buffer. Sedimentation velocity (Figure 2a,b) and the elution profiles from SEC MALS (Figure 3a,b) show unimodal behaviour for both HA and TSP. Extrapolation of the sedimentation coefficients to zero concentration (Figure 2c,d) yield $s_{20, w}$ values of $(4.7 \pm 0.2) S$ and $(5.4 \pm 0.2) S$, with concentration dependence or Gralén " $k_{\mathrm{s}}$ " parameter values, respectively of $(1171 \pm 20) \mathrm{mL} / \mathrm{g}$ and $(240 \pm 30) \mathrm{mL} / \mathrm{g}$. The lower value for $k_{\mathrm{s}}$ for TSP is commensurate with the presence of weak self-associative effects we previously reported [14] which has an opposing effect on the concentration dependence to hydrodynamic nonideality.

SEC-MALS elution profiles for HA and TSP respectively are given in Figure $3 a, b$, and corresponding typical Zimm extrapolations for specific elution volumes or times are given in Figure 3c,d. Weight average molar masses $M_{\mathrm{w}}$ of $(680 \pm 30) \mathrm{kg} / \mathrm{mol}$ and $(830 \pm 30) \mathrm{kg} / \mathrm{mol}$ for the HA and TSP preparations are obtained, with low polydispersities commensurate for an optical formulation.

Corresponding viscosity plots obtained with the Ostwald capillary viscometer are shown in Figure 4 for HA (Figure 4a) and TSP (Figure $4 \mathrm{~b}$ ) respectively, yielding values of (1475 \pm 30$) \mathrm{mL} / \mathrm{g}$ and $(675 \pm 20) \mathrm{mL} / \mathrm{g}$.

Values for the molar mass and intrinsic viscosity for the Farmigea hyaluronic acid preparations (Table 1) are somewhat lower than we analysed previously from a different source [7,8]. By contrast the tamarind seed gum preparations gave similar results to what we have found before [14,29]. The differential pressure Viscostar (Wyatt Technology, Santa Barbara USA) viscometer attached on-line to SEC allows relative viscosities $\eta_{\text {rel }}\left(t_{e}\right)$ to be recorded as a function of elution volume (or elution time $\left.t_{\mathrm{e}}\right)$, and also the corresponding molar masses $M_{\mathrm{w}}\left(t_{e}\right)$. 

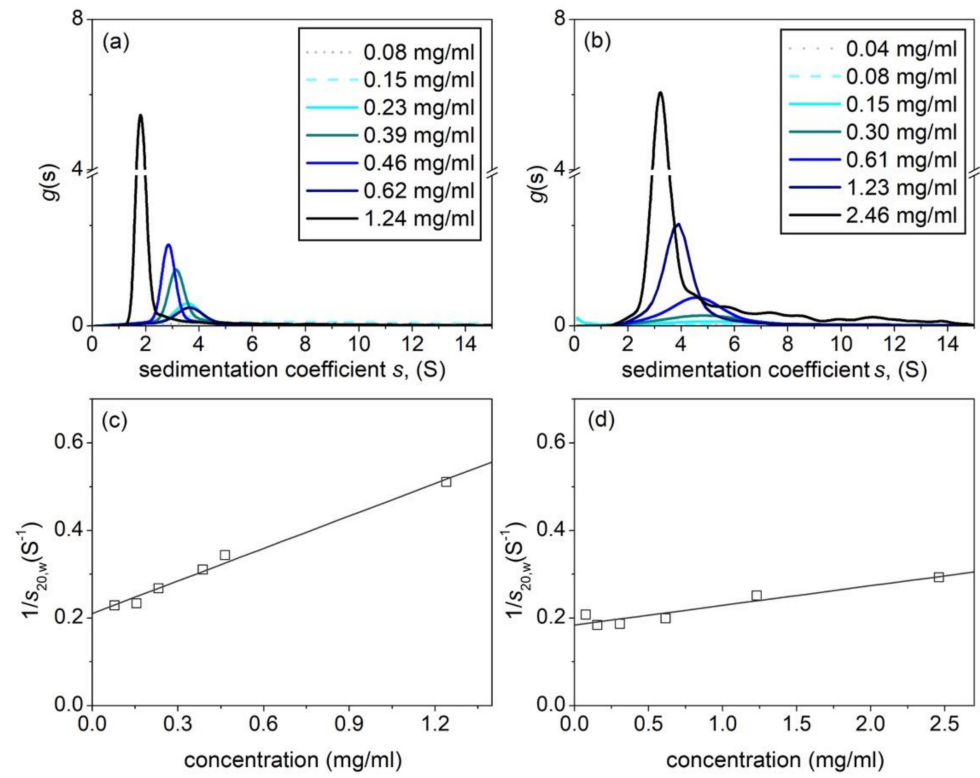

Figure 2. Sedimentation coefficient distributions. (a) Hyaluronic acid, HA. (b) Tamarind seed polysaccharide, TSP. (c) Corresponding concentration extrapolation to zero concentration to eliminate nonideality effects for $\mathrm{HA}(\mathrm{d})$ Corresponding plot for TSP. Solution $\mathrm{pH}=6.8, \mathrm{I}=0.1$, temperature $=20.0^{\circ} \mathrm{C}$.

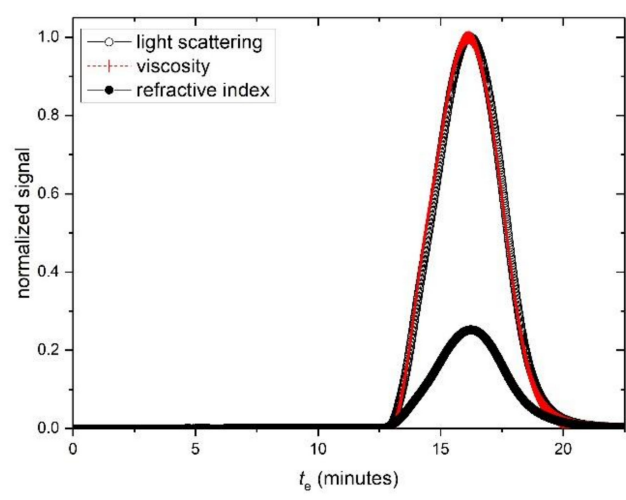

(a)

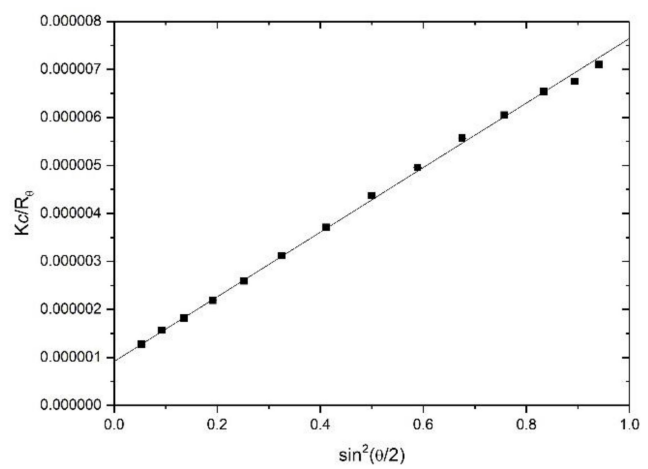

(c)

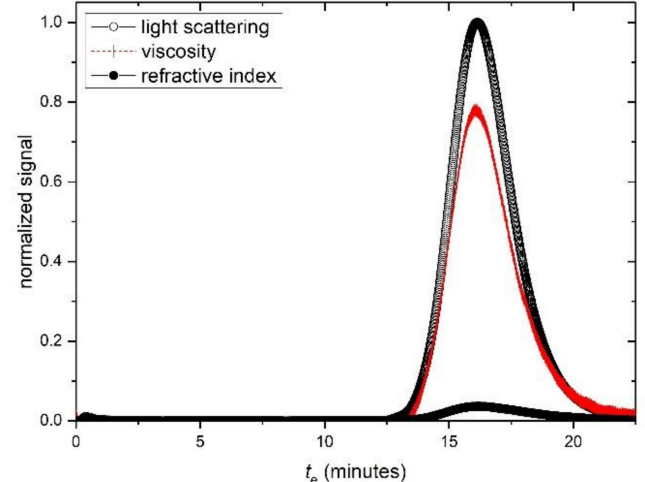

(b)

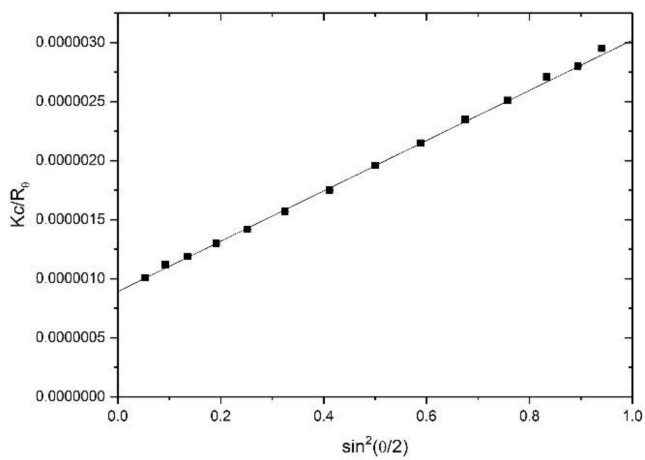

(d)

Figure 3. Size exclusion chromatography-multiangle light scattering (SEC-MALS) elution profiles for (a) hyaluronic acid, HA and (b) tamarind seed polysaccharide, TSP. Solid black circles: light scattering signal at a scattering angle $\theta=90^{\circ}$. Open circles: concentration (refractive index) signal; dashed line: differential pressure (viscosity) signal; $t_{\mathrm{e}}=$ elution time. (c) Zimm fit of $\mathrm{Kc} / \mathrm{R}_{\theta}$ (see text for definitions) vs $\sin ^{2}(\theta / 2)$ for HA, at a single elution time $t_{\mathrm{e}}$. (d) Corresponding plot for TSP. Solution $\mathrm{pH}=6.8, \mathrm{I}=0.1$, temperature $=20.0^{\circ} \mathrm{C}$. 


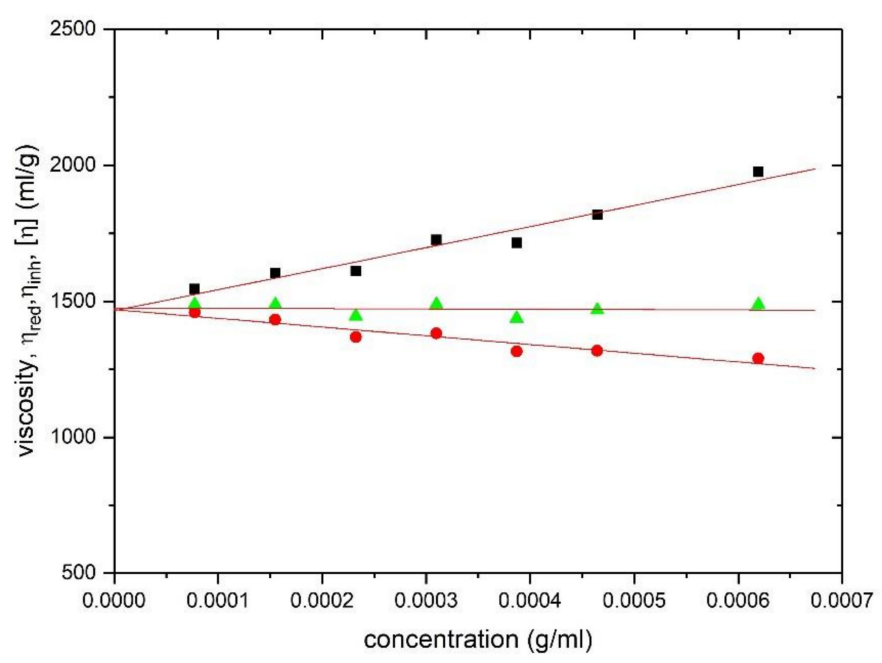

(a)

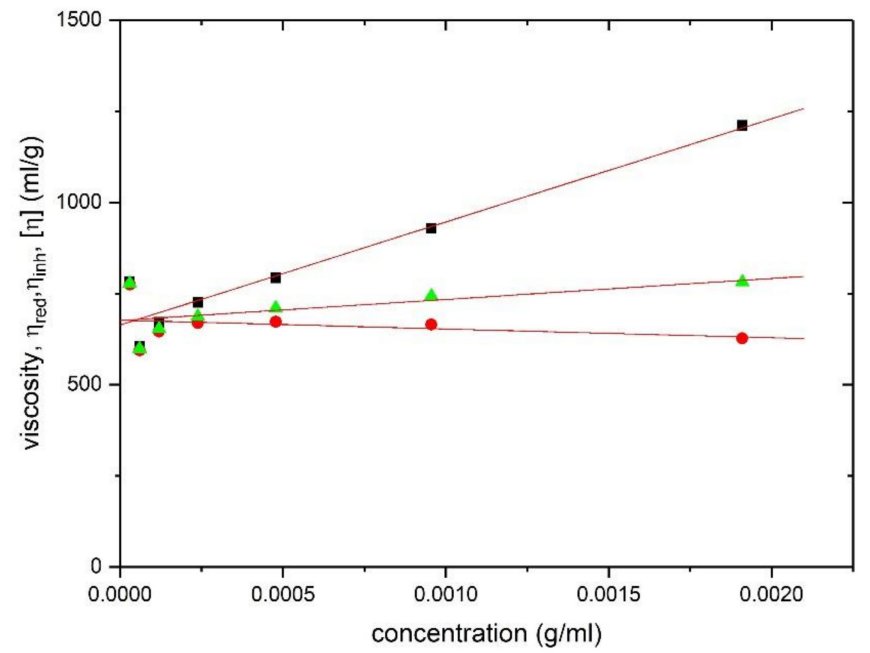

(b)

Figure 4. Evaluation of the intrinsic viscosity [ $\eta$ ] from Ostwald viscometry: (a) hyaluronic acid and (b) tamarind seed polysaccharide. Squares: Huggins' extrapolation; triangles: Solomon-Ciuta; circles: Kraemer extrapolation. Solution $\mathrm{pH}=6.8, \mathrm{I}=0.1$, temperature $=(20.00 \pm 0.05){ }^{\circ} \mathrm{C}$.

Since the concentration is known also for each value of $t_{e}$ from the refractive index detection, this enables an estimate for $[\eta]\left(t_{e}\right)$ to be obtained from equation (9). Mark-Houwink-Kuhn-Sakurada (MHKS) plots of $\log [\eta]\left(t_{e}\right)$ vs $\log M_{\mathrm{w}}\left(t_{e}\right)$ for HA and TSP respectively are given in (Figure $4 \mathrm{a}, \mathrm{b}$ ), enabling evaluation of the MHKS conformation parameter $a$ :

$$
[\eta]\left(t_{\mathrm{e}}\right)=M_{\mathrm{W}}\left(t_{\mathrm{e}}\right)^{a}
$$

From Figure 5a (HA) a value of $a$ of 1.1 is obtained, corresponding to a stiff extended conformation, although $>M=800 \mathrm{~kg} / \mathrm{mol}$ a lower value is obtained ( $a \sim 0.56)$ corresponding to a flexible random coil conformation. Figure $5 \mathrm{~b}$ we obtain $a=0.63$ for TSP, also corresponding to a flexible random coil. 


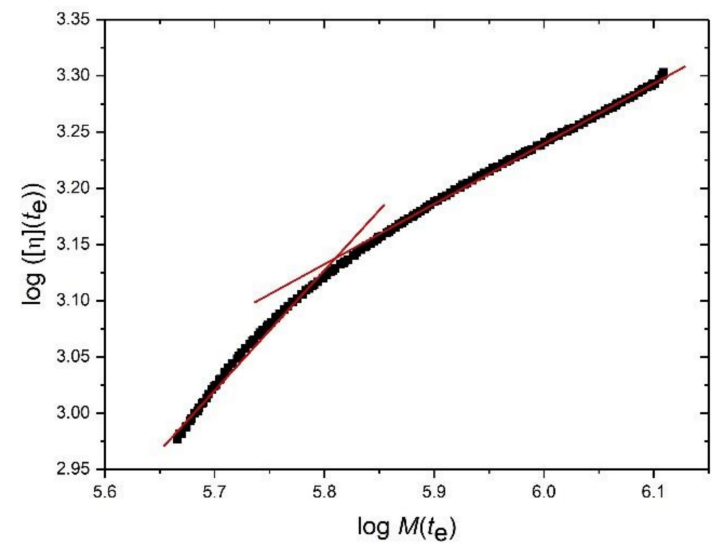

(a)

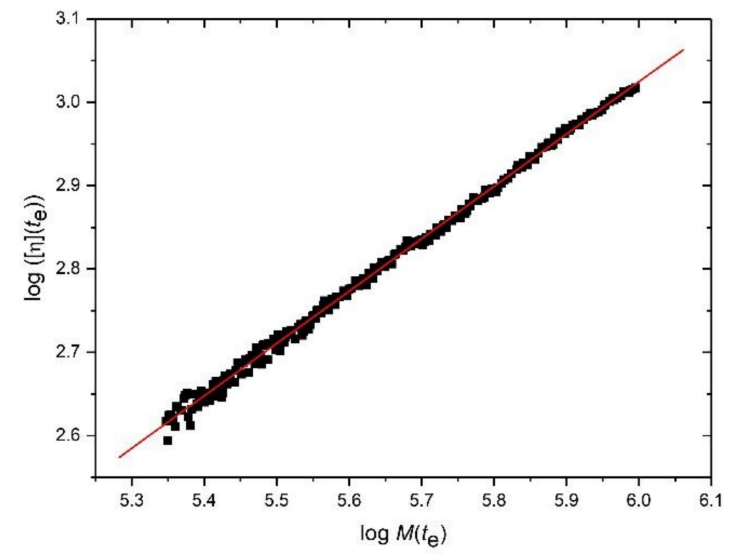

(b)

Figure 5. Mark-Houwink-Kuhn-Sakurada plots of log intrinsic viscosity vs log molecular weight $M\left(t_{\mathrm{e}}\right)$ at corresponding elution times $t_{\mathrm{e}}$ : (a) hyaluronic acid and $(\mathbf{b})$ tamarind seed gum. Solution $\mathrm{pH}=$ $6.8, \mathrm{I}=0.1$, temperature $=(20.0 \pm 0.1){ }^{\circ} \mathrm{C}$.

\subsection{Hydrodynamic Behaviour of Mixtures of HA and TSP}

Figure 6a shows the SEC-MALS profile for a mixture of HA with TSP. One can see a slight shift to lower elution times (higher molar masses) relative to HA and TSP by themselves (Figure 3a,b) with a shoulder at lower elution time suggestive of some degree of complexation or weak interaction. Analysis using ASTRA software shows agreement in the measured $M_{\mathrm{W}}(=720 \pm 30) \mathrm{kg} / \mathrm{mol}$ compared with the predicted value of $755 \mathrm{~kg} / \mathrm{mol}$.

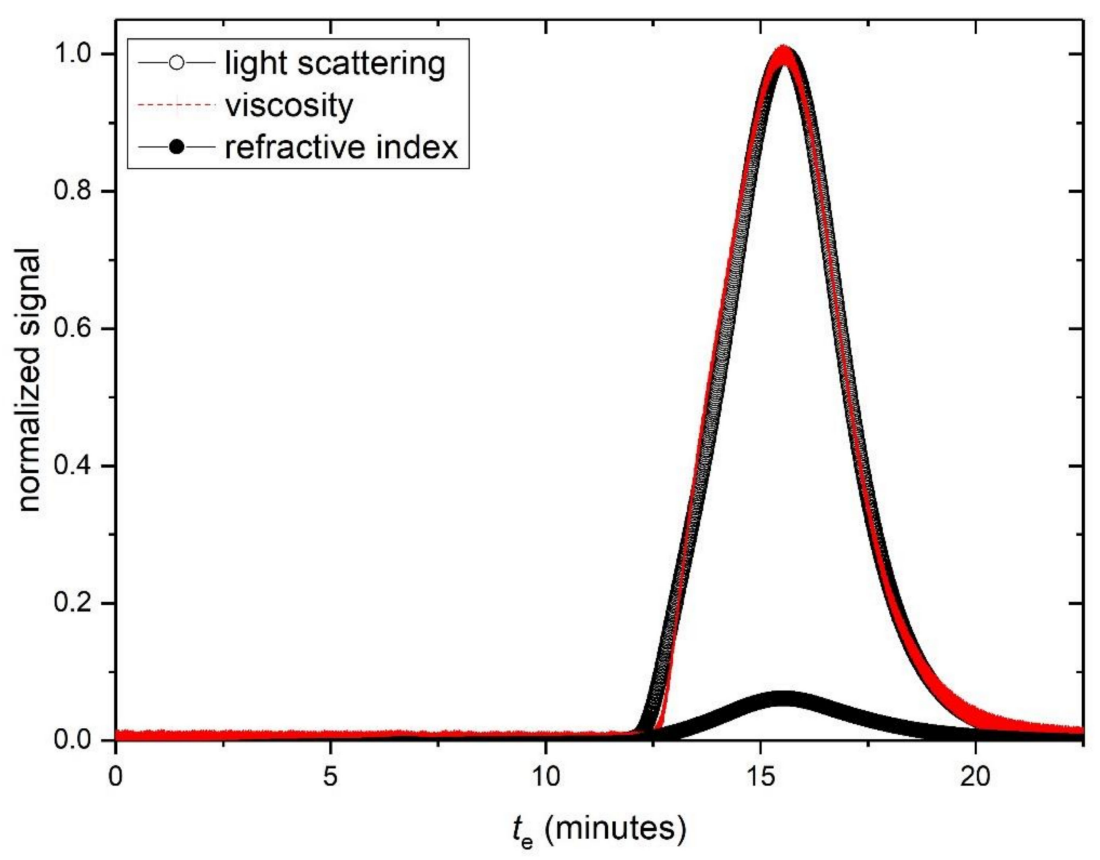

(a)

Figure 6. Cont. 


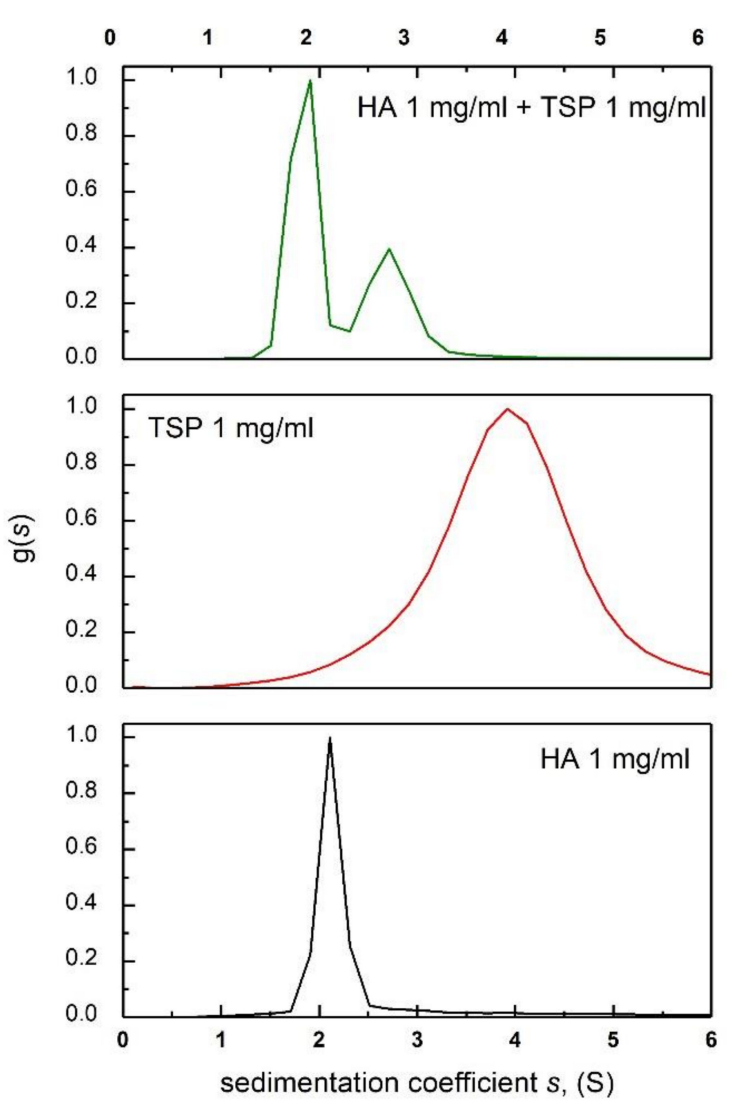

(b)

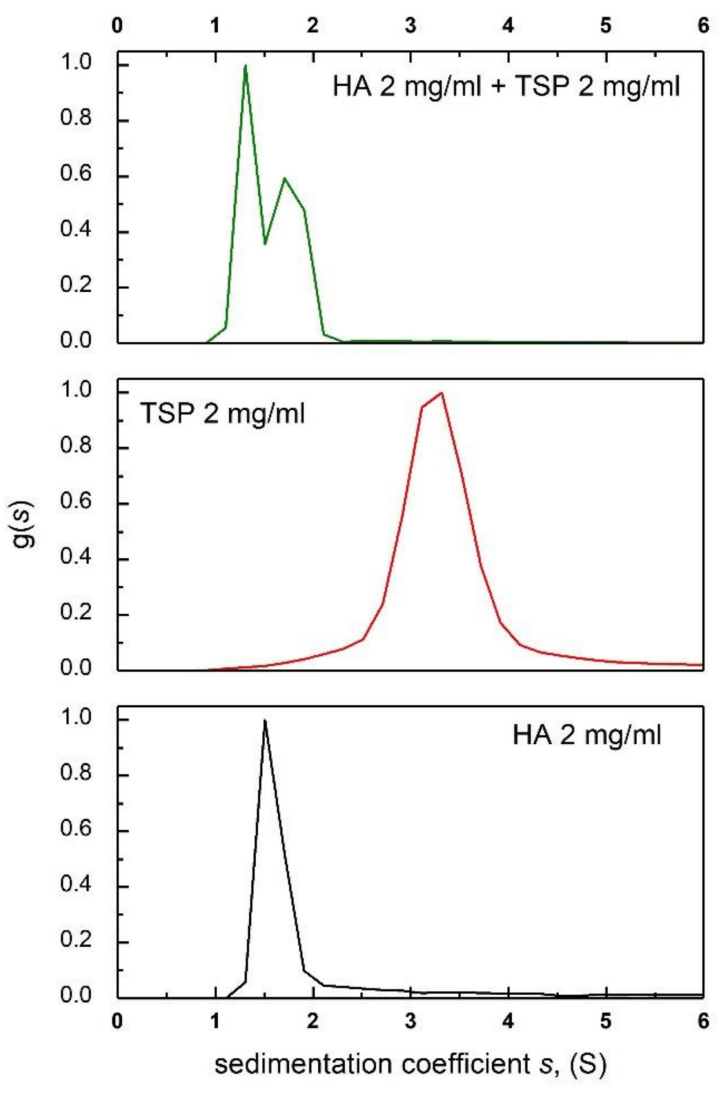

(c)

Figure 6. (a) Elution profiles for a 1:1 mixture of HA to TSP in 0.1M, pH 6.8 PBS buffer. Solid circles-light scattering $90^{\circ}$ signal. Open circles-concentration (refractive index) signal. Dashed line-relative viscosity signal. Concentration of $\mathrm{HSA}=1 \mathrm{mg} / \mathrm{mL}$, and TSP $=1 \mathrm{mg} / \mathrm{mL}$. (b) Sedimentation coefficient distributions for HA (black), TSP (red) and HA-TSP mixture (green). Concentrations of HA, TSP $1 \mathrm{mg} / \mathrm{mL}$. (c) As (b) but concentrations of HA, TSP $=2.0 \mathrm{mg} / \mathrm{mL}$.

These observations are reinforced by the results from intrinsic viscosity. Table 2 shows the comparison of the theoretical intrinsic viscosity calculated from the ratio of HA to TSP in each mixture with varying ratios (the HA:TSP ratios $=3: 1,1: 1$ and 3:1), and the actual intrinsic viscosity obtained experimentally from the capillary viscometry. It is clear that there is no significant increase (HA:TSP $=$ $1: 1$ and $1: 3)$.

Table 2. Measured intrinsic viscosities for HA:TSP mixtures compared with the theoretically predicted (based on values from Table 1) if there was no interaction.

\begin{tabular}{|c|c|c|}
\hline HA:TSP ratio & {$[\eta]$} & 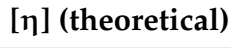 \\
\hline $1: 3$ & $780 \mathrm{~mL} / \mathrm{g}$ & $940 \mathrm{~mL} / \mathrm{g}$ \\
\hline $1: 1$ & $1100 \mathrm{~mL} / \mathrm{g}$ & $1075 \mathrm{~mL} / \mathrm{g}$ \\
\hline $3: 1$ & $1180 \mathrm{~mL} / \mathrm{g}$ & $1200 \mathrm{~mL} / \mathrm{g}$ \\
\hline
\end{tabular}

\section{Conclusions}

The present findings of this hydrodynamic study using mixtures of hyaluronic acid and tamarind seed polysaccharides implies there is no incompatibility in solutions of the two, at concentrations used in popular formulations to help supplement reduced lacrymal fluid/ ocular mucin in an aging population. Earlier observations using NMR spectroscopy [1] have demonstrated a synergistic interaction between the two polysaccharides. The present study complements those observations by showing that no 
large aggregate or supramolecular formation was evident, reassuring for formulations involving the two polymers.

Author Contributions: Conceptualization and supervision, S.E.H., M.K.P.-J.; data curation, T.C., T.M., V.D.; sample origination and application S.O. All authors have read and agreed to the published version of the manuscript.

Funding: V.D. is supported by a Research Fellowship from the United Kingdom Engineering and Physical Sciences Research Council.

Conflicts of Interest: The authors declare no conflict of interest.

\section{References}

1. Uccello-Barretta, G.; Nazzi, S.; Zambito, Y.; Di Colo, G.; Balzano, F.; Sanso, M. Synergistic interaction between TS-polysaccharide and hyaluronic acid: Implications in the formulation of eye drops. Int. J. Pharm. 2010, 395, 122-131. [CrossRef] [PubMed]

2. Lee, D.; Lu, Q.; Sommerfeld, S.D.; Chan, A.; Menon, N.G.; Schmidt, T.A.; Elisseeff, J.H.; Singh, A. Targeted delivery of hyaluronic acid to the ocular surface by a polymer-peptide conjugate system for dry eye disease. Acta Biomater. 2017, 55, 163-171. [CrossRef] [PubMed]

3. Luo, L.; Lai, J. Epigallocatechin gallate-loaded gelatin-g-poly(N-isopropylacrylamide) as a new ophthalmic pharmaceutical formulation for topical use in the treatment of dry eye syndrome. Sci. Rep. 2017, 7, 9380. [CrossRef] [PubMed]

4. Luo, L.-J.; Nguyen, D.D.; Lai, J.-Y. Long-acting mucoadhesive thermogels for improving topical treatments of dry eye disease. Mater. Sci. Eng. C 2020, 115, 111095. [CrossRef]

5. Lai, J.-Y.; Luo, L.-J.; Nguyen, D.D. Multifunctional glutathione-dependent hydrogel eye drops with enhanced drug bioavailability for glaucoma therapy. Chem. Eng. J. 2020, 402, 126190. [CrossRef]

6. Barabino, S.; Rolando, M.; Nardi, M.; Bonini, S.; Aragona, P.; Traverso, C.E. The effect of an artificial tear combining hyaluronic acid and tamarind seeds polysaccharide in patients with moderate dry eye syndrome: A new treatment for dry eye. Eur. J. Ophthalmol. 2014, 24, 173-178. [CrossRef]

7. Hokputsa, S.; Jumel, K.; Alexander, C.; Harding, S.E. A comparison of molecular mass determination of hyaluronic acid using SEC/MALLS and sedimentation equilibrium. Eur. Biophys. J. 2003, 32, 450-456. [CrossRef]

8. Hokputsa, S.; Jumel, K.; Alexander, C.; Harding, S.E. Hydrodynamic characterisation of chemically degraded hyaluronic acid. Carbohydr. Polym. 2003, 52, 111-117. [CrossRef]

9. Rah, M.J. A review of hyaluronan and its ophthalmic applications. Optom. J. Am. Optom. Assoc. 2011, 82, 38-43. [CrossRef]

10. Johnson, M.E.; Murphy, P.J.; Boulton, M. Effectiveness of sodium hyaluronate eyedrops in the treatment of dry eye. Graefe's Arch. Clin. Exp. Ophthalmol. 2006, 244, 109-112. [CrossRef]

11. Hammer, M.E.; Burch, T.G. Viscous corneal protection by sodium hyaluronate, chondroitin sulfate, and methylcellulose. Investig. Ophthalmol. Vis. Sci. 1984, 25, 1329-1332.

12. Semenzato, A.; Costantini, A.; Baratto, G. Green polymers in personal care products: Rheological properties of tamarind seed polysaccharide. Cosmetics 2015, 2, 1-10. [CrossRef]

13. Rolando, M.; Valente, C. Establishing the tolerability and performance of tamarind seed polysaccharide (TSP) in treating dry eye syndrome: Results of a clinical study. BMC Ophthalmol. 2007, 7, 1-8. [CrossRef] [PubMed]

14. Patel, T.R.; Morris, G.A.; Ebringerova, A.; Vodenicarova, M.; Velebny, V.; Ortega, A.; de la Torre, J.G.; Harding, S.E. Global conformation analysis of irradiated xyloglucans. Carbohydr. Polym. 2008, 74, 845-851. [CrossRef]

15. Lian, L.-Y. NMR studies of protein-ligand interactions. In Protein-Ligand Interactions, Structure and Spectroscopy: A Practical Approach; Harding, S.E., Chowdhry, B.Z., Eds.; Oxford University Press: Oxford, UK, 2001; pp. 383-405.

16. Uccello-Barretta, G.; Balzano, F.; Vanni, L.; Sanso, M. Mucoadhesive properties of tamarind-seed polysaccharide/hyaluronic acid mixtures: A nuclear magnetic resonance spectroscopy investigation. Carbohydr. Polym. 2013, 91, 568-572. [CrossRef] [PubMed]

17. Harding, S.E. The Svedberg Lecture 2017. From nano to micro: The huge dynamic range of the analytical ultracentrifuge for characterising the sizes, shapes and interactions of molecules and assemblies in Biochemistry and Polymer Science. Eur. Biophys. J. 2018, 47, 697-707. [CrossRef] [PubMed] 
18. Harding, S.E.; Adams, G.G.; Almutairi, F.; Alzahrani, Q.; Erten, T.; Kök, M.S.; Gillis, R.B. Ultracentrifuge methods for the analysis of polysaccharides, glycoconjugates, and lignins. Methods Enzymol. 2015, 562, 391-439. [PubMed]

19. Yang, Y.; Chang, S.; Bai, Y.; Du, Y.; Deng-Guang, Y. Electrospun triaxial nanofibers with middle blank cellulose acetate layers for accurate dual-stage drug release. Carbohydr. Polym. 2000, 243, 116477. [CrossRef]

20. Wang, M.; Hai, T.; Feng, Z.; Yu, D.-G.; Yang, Y.; Bligh, S.W.A. The relationships between the working fluids, process characteristics and products from the modified coaxial electrospinning of zein. Polymers 2019, 11, 1287. [CrossRef]

21. Wang, K.; Wen, H.-F.; Yu, D.-G.; Yang, Y.; Zhang, D.-F. Electrosprayed hydrophilic nanocomposites coated with shellac for colon-specific delayed drug delivery. Mater. Des. 2018, 143, 248-255. [CrossRef]

22. Yoon, W.H.; Lee, K.H. Rheological properties and efficacy of the formulation of hyaluronic acid with tamarind seed polysaccharide for arthritis. Biorheology 2019, 56, 31-38. [CrossRef] [PubMed]

23. Green, A.A. The preparation of acetate and phosphate buffer solutions of known $\mathrm{pH}$ and ionic strength. J. Am. Chem. Soc. 1933, 55, 2331-2336. [CrossRef]

24. Wang, Q.; Ellis, P.R.; Ross-Murphy, S.B.; Burchard, W. Solution characteristics of the xyloglucan extracted from Detarium senegalense Gmelin. Carbohydr. Polym. 1997, 33, 115-124. [CrossRef]

25. Dam, J.; Schuck, P. Calculating sedimentation coefficient distributions by direct modeling of sedimentation velocity concentration profiles. Methods Enzymol. 2004, 384, 185-212. [CrossRef]

26. Schachman, H.K. Ultracentrifugation Biochemistry; Academic Press: New York, NY, USA; London, UK, 1950.

27. Gralén, N. Sedimentation and Diffusion Measurements on Cellulose and Cellulose Derivatives. Ph.D. Thesis, University of Uppsala, Uppsala, Sweden, 1994.

28. Wyatt, P.J. Combined differential light scattering with various liquid chromatography separation techniques. In Laser Light Scatt Biochemistry; Harding, S.E., Sattelle, D.B., Bloomfield, V.A., Eds.; Royal Society of Chemistry: Cambridge, UK, 1992; pp. 35-38.

29. Picout, D.R.; Ross-Murphy, S.B.; Errington, N.; Harding, S.E. Pressure cell assisted solubilization of xyloglucans: Tamarind seed polysaccharide and (gum). Biomacromolecules 2003, 4, 799-807. [CrossRef]

30. Zimm, B.H. The Scattering of light and the radial distribution function of high polymer Solutions. J. Chem. Phys. 1948, 16, 1093-1099. [CrossRef]

31. Harding, S.E.; Tombs, M.P.; Adams, G.G.; Paulsen, B.S.; Inngjerdingen, K.T.; Barsett, H. An Introduction to Polysaccharide Biotechnology, 2nd ed.; CRC Press: Boca Raton, FL, USA, 2017.

32. Almutairi, F.M.; Erten, T.; Adams, G.G.; Hayes, M.; McLoughlin, P.; Kok, M.S.; Mackie, A.R.; Rowe, A.J.; Harding, S.E. Hydrodynamic characterization of chitosan and its interaction with two polyanions: DNA and xanthan. Carbohydr. Polym. 2015, 122, 359-366. [CrossRef]

33. Harding, S.E. The intrinsic viscosity of biological macromolecules. Progress in measurement, interpretation and application to structure in dilute solution. Prog. Biophys. Mol. Biol. 1997, 68, 207-262. [CrossRef]

34. Huggins, M.L. The viscosity of dilute solutions of long-chain molecules. IV. Dependence on concentration. J. Am. Chem. Soc. 1942, 64, 2716-2718. [CrossRef]

35. Kraemer, E.O. Molecular weights of celluloses and cellulose derivates. Ind. Eng. Chem. 1938, 30, 1200-1203. [CrossRef]

36. Solomon, O.F.; Ciuta, I.Z. Determination de la viscosite intrinseque de solutions de polymeres par une simple determination de la viscosite. J. Appl. Polym. Sci. 1962, 7, 683-686. [CrossRef]

(C) 2020 by the authors. Licensee MDPI, Basel, Switzerland. This article is an open access article distributed under the terms and conditions of the Creative Commons Attribution (CC BY) license (http://creativecommons.org/licenses/by/4.0/). 